\title{
Statin in Combined With Xuezhikang Capsules Get More Lipid- Regulating Effective Than Statin Only: A Systematic Review and Meta-Analysis
}

Dongxiong Chen ( $\sim$ dongxiong163@163.com)

Guangzhou Hospital of Traditional Chinese Medicine https://orcid.org/0000-0003-4326-3188

Huiyan Feng

The Third Affiliated Hospital of Guangzhou Medical University

Yigen Li

Guangzhou Hospital of Traditional Chinese Medicine

Jinzhu Huang

Tranditional Chinese Medicine Hospital of Guangdong Province

\section{Research}

Keywords: Xuezhikang Capsule, Statin, Hyperlipidemia, Meta-analysis

Posted Date: October 18th, 2021

DOI: https://doi.org/10.21203/rs.3.rs-965115/v1

License: (ㅇ) (i) This work is licensed under a Creative Commons Attribution 4.0 International License. Read Full License 


\section{Abstract}

Background: To compare the lipid-regulating effects and safety of statin combined with Xuezhikang capsules and statin used alone for hyperlipidemia.

Methods: CNKI, Wanfang database, VIP Chinese Journals, PubMed, Embase, and Cochrane library were searched to comprehensively collect and screen RCTs of Xuezhikang combined with statin compared with statin used alone for lipid modifying treatment in hyperlipidemia patients from the database built as of July 2020, and the Cochrane 5.1.0 quality evaluation form was used to evaluate the quality of the included literature and The Cochrane 5.1.0 quality assessment form was used to evaluate the quality of the included literature and bias analysis, extract basic study information, primary and secondary outcome indicators, and meta-analysis of the outcome indicators was performed using RevMan 5.3.

Results: A total of 14 studies with a total of 2042 patients were included, and the quality of the included studies was low to medium. QEffectiveness rate: $\mathrm{OR}=3.63,95 \% \mathrm{Cl}[2.69,4.90], P<0.00001$; Funnel plot: all within the funnel, but not in accordance with the principle of "aggregation at the top and dispersion at the bottom". $\otimes$ Total cholesterol: $\mathrm{MD}=-0.61,95 \% \mathrm{CI}[-0.84,-0.39], P<0.00001$, The forest plots of each subgroup are to the left, $P<0.05$. $\otimes$ Triglycerides: $\mathrm{MD}=-0.30,95 \% \mathrm{Cl}[-0.41,-0.19], P<0.00001$, The forest plots of each subgroup are to the left, $P<0.05$. 0.05. $\otimes \mathrm{LDL}: \mathrm{MD}=-0.33,95 \% \mathrm{CI}[-0.46,-0.20], P<0.00001$, The forest plots of each subgroup are to the left, $P<0.05 \mathrm{in}$ atorvastatin and fluvastatin groups, $P=0.09$ in simvastatin group. $\otimes \mathrm{HDL}: \mathrm{MD}=0.23,95 \% \mathrm{Cl}[0.12,0.35], P<0.00001$, The forest plots of each subgroup are to the right, $P<0.05$. 6) Adverse effects: OR=0.32, 95\% $\mathrm{Cl}[0.19,0.55], P<0.0001$.

Conclusion: The combination of statin with Xuezhikang capsule has better effect on lipid regulation in patients with hyperlipidemia, and can effectively reduce the incidence of adverse events and has better safety. It is recommended that the treatment of Xuezhikang combined with statin can be used as a safer and more effective treatment for patients with hyperlipidemia.

\section{Background}

With the increasing standard of living of people, hyperlipidemia has become a common disease in modern society and has become a major risk factor for diseases such as atherosclerosis ${ }^{[1]}$. With childhood obesity becoming an epidemic in certain parts of the United States $^{[2]}$, hyperlipidemia is either directly or indirectly affecting people's health. And the regulation and stabilization of lipid levels has become one of the health care behaviours in modern daily life ${ }^{[3]}$. Statins are the first-line of lipid-modifying therapy ${ }^{[4]}$, but their intensive use can have borderline effects ${ }^{[5]}$, and the relationship between benefits and risks and economic benefits still needs to be studied $^{[6-8]}$. Xuezhikang Capsules(Xuezhikang) represent a natural statin lipid-lowering drug, whose main ingredient is red yeast, refined in a standard GMP process and containing 13 natural compound statins ${ }^{[9]}$ and its toxicity is extremely low ${ }^{[10]}$. Compared with synthetic statins, Xuezhikang is not effective in the comprehensive regulation of blood lipids and reducing the incidence of adverse reactions, which not only can be used as a first-line clinical drug ${ }^{[11]}$, but also can improve the benefits ${ }^{[12]}$ and reduce the risks of intensive statin use ${ }^{[13]}$. To further investigate the efficacy and adverse effects of statins combined with Xuezhikang in patients with hyperlipidemia, this study conducts a systematic review and meta-analysis of the relevant literature, with a view to provide evidencebased medicine for clinical application.

\section{Materials And Methods}

\subsection{Search Strategy}

\subsubsection{Databases}

A systematic literature review was conducted by using the databases CNKI, Wanfang database, VIP Chinese Journals, PubMed/Medline, Embase, Cochrane Library. Furthermore, the reference list of the relevant articles was manually searched.

\subsubsection{Search Time and language}

From January 1998 to July 2020 with no language restriction.

\subsubsection{Search Formula}

Page 2/20 
Take PubMed as an example: Title/ Abstract: Xuezhikang[Mesh] AND (statins[Mesh] OR atorvastatin[Title/Abstract] OR Lipitor[Title/Abstract] OR atrovastatin[Title/Abstract] OR atovastatin[Title/Abstract] OR rosuvastatin[Title/Abstract] OR Crestor[Title/Abstract] OR Rosuvastatin Calcium[Title/Abstract] OR Rosuvastatin[Title/Abstract] OR Simvastatin[Title/Abstract] OR Fluvastatin[Title/Abstract] OR pravastatin[Title /Abstract] OR Pravachol[Title/Abstract] OR provastatin[Title/Abstract] OR Mevalotin[Title/Abstract] OR fluvastatin[Title/Abstract]) AND ( hyperlipidemia[Mesh] OR hyperlipemia[Title/Abstract]) AND (Randomized controlled trial[Publication type] OR randomized[Title/Abstract] OR placebo[Title/Abstract])

\subsection{Registration Information}

This systematic review and meta-analysis complies with the PRISMA Statement ${ }^{[14]}$ and is registered in PROSPERO(No. CRD42020200277).

\subsection{Inclusion and Exclusion Criteria}

\subsubsection{Subjects}

QDiagnostic criteria: "Guidelines for Clinical Research on New Chinese Medicines", "Guidelines for the Prevention and Treatment of Dyslipidemia in Chinese Adults", "Relevant Judgment Criteria Developed by the American Cholesterol Education Program Committee", "Practical Internal Medicine". 『Sex, age and comorbidities were not limited.

\subsubsection{Intervention}

The trial group was treated with Xuezhikang capsules combined with statins, and the control group was treated with the same type and dose of statins as the trial group.

\subsubsection{Outcome indicators}

Primary efficacy indicator: treatment efficiency. Secondary efficacy indicators: 1. total cholesterol(TC); 2. triglycerides(TG); 3. low density lipoprotein(LDLC); 4. high density lipoprotein(HDLC); 5. number of adverse events.

\subsubsection{Study Type}

Randomized controlled trial(RCT), no matter whether to adopt blinded or allocation concealment, language was limited to Chinese or English.

\subsubsection{Exclusion Criteria}

هFor patients who have taken other drugs affecting lipid metabolism concurrently during treatment. \&Literature for which complete data are not available.

\subsection{Literature Screening and Data Extraction}

Two researchers(Chen and Feng) independently screened the literature according to the inclusion and exclusion criteria and crosschecked it, using a pre-designed data extraction form to extract information, including basic information about the study, study methods, observation of subjects, intervention and control measures, indicators, outcomes and occurrence of adverse effects. In case of disagreement, it was resolved in consultation with the third researcher $(\mathrm{Li})$. If the information reported in the study was incomplete, further contact was made with the author to obtain it, and the study was excluded if relevant data were not eventually obtained.

\subsection{Literature Evaluation}

The Cochrane 5.1.0 Quality Assessor's Manual is used to screen and assess the quality of the literature. Judgements of bias (selection bias, implementation bias, measurement bias, follow-up bias, reporting bias and other biases) were made as "low risk/uncertain/high risk".

\subsection{Statistical Analysis}


Meta-analysis was performed by using RevMan 5.3 software. The odds ratio(OR) was measured using the MH algorithm for count data and the mean difference(MD) was measured using the IV algorithm for continuous variable data with $95 \%$ confidence intervals $(\mathrm{Cl})$. Heterogeneity between the results of each included study was tested by Q-test and $\mathrm{I}^{2}$-test. We will use Cochrane manual thresholds to explain $I^{2}$-test ${ }^{[15]}$ and Q-test ${ }^{[16]}$. $\left(1^{2}: 0 \sim 40 \%\right.$, may not be important;30\% 60\%, which may represent moderate heterogeneity; $50 \% \sim 90 \%$, may represent significant heterogeneity; $75 \% \sim 100 \%$,with considerable heterogeneity. $P$ of Q-test: $>0.1$, low heterogeneity; $<0.1$, high heterogeneity.) If Q-est: $P>0.1$ or $I^{2}$ test: $I^{2}<50 \%$, fixed effects model(FE) was used; if Q-test: $P<0.1$ or $I^{2}$ test: $\mathrm{I}^{2}>50 \%$, random-effects model $(\mathrm{RE})$ was used, and sources of heterogeneity were identified by subgroup method or single-study exclusion method to reduce heterogeneity. $P<0.05$ for the combined effect indicator indicates a statistically significant difference. When the number of included studies was $\geq 10$, an inverted funnel plot analysis was performed to detect publication bias, using the effect indicators of the included studies as horizontal coordinates and the inverse of the log standard error(SE) as vertical coordinates. Descriptive analysis was used when data heterogeneity due to other reasons was clearly not possible to combine for analysis.

\section{Results}

\subsection{Literature Search Results}

A total of 992 papers were initially reviewed, and after reading the abstracts and full text, 14 RCTs ${ }^{[17-30]}$ were eventually included, with the process shown in Figure 1.

\subsection{Basic Characteristics of the Included Studies}

All the studies included 2042 patients, with 1022 in the trial group and 1020 in the control group. The statins involved included: atorvastatin, simvastatin, rosuvastatin and fluvastatin, all of which are at moderate doses according to guidelines. Study duration ranged from 4 to 12 weeks. All studies were funded by grants, as detailed in Table 1(Additional file 1).

Table 1 Clinical characteristics of 14 studies in the meta-analysis 


\begin{tabular}{|c|c|c|c|c|c|c|c|c|c|c|c|}
\hline \multirow[t]{2}{*}{$\begin{array}{l}\text { Documentar- } \\
\text { y sources }\end{array}$} & \multicolumn{2}{|c|}{$\begin{array}{l}\text { Sample } \\
\text { size }\end{array}$} & \multicolumn{2}{|c|}{ Age mean/year } & \multirow{2}{*}{$\begin{array}{l}\text { Low } \\
\text { fat } \\
\text { diet }\end{array}$} & \multicolumn{2}{|c|}{ Interventions } & \multirow[t]{2}{*}{ Treatment/week } & \multicolumn{2}{|c|}{$\begin{array}{l}\text { Adverse } \\
\text { reactions }\end{array}$} & \multirow[t]{2}{*}{$\begin{array}{l}\text { Ending } \\
\text { indicators }\end{array}$} \\
\hline & 1 & II & 1 & II & & 1 & II & & 1 & II & \\
\hline $\begin{array}{l}\text { Yanjun Fu } \\
2017\end{array}$ & 75 & 75 & $63.2 \pm 9.3$ & $61.8 \pm 9.3$ & I & $\begin{array}{l}\mathrm{A} \\
0.6 \mathrm{~g} \\
\text { bid+ll }\end{array}$ & $\begin{array}{l}\text { B } \\
10 \mathrm{mg} \\
\text { qd }\end{array}$ & 12 & 5 & 4 & abcde \\
\hline $\begin{array}{l}\text { Yue Han } \\
2019\end{array}$ & 36 & 36 & $70.86 \pm 3.77$ & $69.86 \pm 3.28$ & Yes & $\begin{array}{l}\mathrm{A} \\
0.6 \mathrm{~g} \\
\text { bid+ll }\end{array}$ & $\begin{array}{l}\mathrm{D} \\
5 \mathrm{mg} \\
\mathrm{qd}\end{array}$ & 12 & / & / & abce \\
\hline $\begin{array}{l}\text { Gongyu Hu } \\
2015\end{array}$ & 60 & 60 & 53.1 & 57.5 & Yes & $\begin{array}{l}\mathrm{A} \\
0.6 \mathrm{~g} \\
\text { bid+ll }\end{array}$ & $\begin{array}{l}\text { B } \\
10 \mathrm{mg} \\
\mathrm{qn}\end{array}$ & 8 & 6 & 7 & abcde \\
\hline $\begin{array}{l}\text { Chonghua } \\
\text { Jiang } 2012\end{array}$ & 85 & 85 & 61. $7 \pm 6.9$ & $61.1 \pm 7.4$ & Yes & $\begin{array}{l}\mathrm{A} \\
1.2 \mathrm{~g} \\
\mathrm{qn}+\mathrm{Il}\end{array}$ & $\begin{array}{l}\mathrm{C} \\
10 \mathrm{mg} \\
\mathrm{qd}\end{array}$ & 12 & / & / & abcde \\
\hline $\begin{array}{l}\text { Chanjuan } \\
\text { Liu } 2018\end{array}$ & 52 & 52 & $58.7 \pm 3.8$ & $58.5 \pm 4.1$ & Yes & $\begin{array}{l}\mathrm{A} \\
0.6 \mathrm{~g} \\
\text { bid+ll }\end{array}$ & $\begin{array}{l}\text { B } \\
20 \mathrm{mg} \\
\mathrm{qd}\end{array}$ & 8 & 0 & 1 & abcde \\
\hline $\begin{array}{l}\text { Chunhua } \\
\text { Qin } 2013\end{array}$ & 40 & 40 & $58 \pm 20.9$ & $57 \pm 22.1$ & None & $\begin{array}{l}\mathrm{A} \\
0.6 \mathrm{~g} \\
\text { bid+ll }\end{array}$ & $\begin{array}{l}\mathrm{C} \\
10 \mathrm{mg} \\
\mathrm{qn}\end{array}$ & 8 & / & / & abe \\
\hline $\begin{array}{l}\text { Chao Shi } \\
2018\end{array}$ & 62 & 62 & $62.13 \pm 7.27$ & $63.03 \pm 7.52$ & None & $\begin{array}{l}\mathrm{A} \\
0.6 \mathrm{~g} \\
\text { bid+ll }\end{array}$ & $\begin{array}{l}\mathrm{E} \\
40 \mathrm{mg} \\
\mathrm{qd}\end{array}$ & 8 & 5 & 8 & abcde \\
\hline $\begin{array}{l}\text { Xiaojing Sun } \\
2018\end{array}$ & 48 & 48 & $63.34 \pm 7.29$ & $63.39 \pm 7.64$ & / & $\begin{array}{l}\mathrm{A} \\
1.2 \mathrm{~g} \\
\text { bid+ll }\end{array}$ & $\begin{array}{l}\mathrm{C} \\
20 \mathrm{mg} \\
\mathrm{qd}\end{array}$ & 12 & / & / & abcde \\
\hline $\begin{array}{l}\text { Zhen Wang } \\
2012\end{array}$ & 39 & 39 & $59.7 \pm 6.4$ & & Yes & $\begin{array}{l}\text { A } \\
0.6 \mathrm{~g} \\
\text { bid + } \\
\text { II }\end{array}$ & $\begin{array}{l}\text { B } \\
10 \mathrm{mg} \\
\mathrm{qn}\end{array}$ & 12 & 1 & 8 & abcde \\
\hline $\begin{array}{l}\text { Hongyun } \\
\text { Zhang } 2010\end{array}$ & 30 & 30 & 72.3 & 73.1 & I & $\begin{array}{l}\mathrm{A} \\
0.6 \mathrm{~g} \\
\text { bid+ll }\end{array}$ & $\begin{array}{l}\mathrm{E} \\
40 \mathrm{mg} \\
\mathrm{qd}\end{array}$ & 4 & / & / & abcde \\
\hline $\begin{array}{l}\text { Li Zhang } \\
2010\end{array}$ & 182 & 180 & $57.2 \pm 10.8$ & $56.5 \pm 11.4$ & Yes & $\begin{array}{l}\mathrm{A} \\
0.6 \mathrm{~g} \\
\text { bid+ll }\end{array}$ & $\begin{array}{l}\mathrm{C} \\
10 \mathrm{mg} \\
\mathrm{qd}\end{array}$ & 8 & 0 & 24 & abcde \\
\hline $\begin{array}{l}\text { Yaping Zhou } \\
2010\end{array}$ & 30 & 30 & 66 & 64 & Yes & $\begin{array}{l}\mathrm{A} \\
0.6 \mathrm{~g} \\
\text { bid+ll }\end{array}$ & $\begin{array}{l}\mathrm{C} \\
20 \mathrm{mg} \\
\mathrm{qd}\end{array}$ & 8 & 1 & 2 & abcde \\
\hline $\begin{array}{l}\text { Zhou Zhou } \\
2010\end{array}$ & 39 & 39 & $52.4 \pm 5.5$ & $53.2 \pm 4.9$ & None & $\begin{array}{l}\mathrm{A} \\
1.2 \mathrm{~g} \\
\mathrm{qn}+1 \mathrm{l}\end{array}$ & $\begin{array}{l}\mathrm{C} \\
10 \mathrm{mg} \\
\mathrm{qn}\end{array}$ & 4 & / & / & abcde \\
\hline $\begin{array}{l}\text { Min Zhou } \\
2017\end{array}$ & 244 & 244 & 52. $6 \pm 5.4$ & $\begin{array}{l}53.1 \pm 5 . \\
5\end{array}$ & / & $\begin{array}{l}\mathrm{A} \\
0.6 \mathrm{~g} \\
\text { bid+ll }\end{array}$ & $\begin{array}{l}\text { B } \\
20 \mathrm{mg} \\
\mathrm{qd}\end{array}$ & 12 & 0 & 34 & abcde \\
\hline
\end{tabular}

Legends: A: Xuezhikang; B: atorvastatin; C: simvastatin; D: rosuvastatin; E: fluvastatin; a: total serum cholesterol level; b:Triglyceride level; c:HDL cholesterol level; d:LDL cholesterol level; e:Effective rate. l:test group; ll: control group. /:not mentioned. qd: once daily; qn: once per night; bid: once in the morning and once in the evening.

\subsection{Quality Evaluation of Included Studies and Risk of Bias Assessment}

All studies were randomized. No sample size estimation or intentionality therapy analysis or blind method was performed. The methodological quality assessment of the included studies is described in detail in Table 2(Additional file 2). The risk of bias of the included studies is assessed in Figures 2. 
Table 2 Evaluation of Methodological Quality of 14 Studies

\begin{tabular}{|c|c|c|c|c|c|c|}
\hline $\begin{array}{l}\text { Documentary } \\
\text { sources }\end{array}$ & $\begin{array}{l}\text { Sample size } \\
\text { estimation }\end{array}$ & $\begin{array}{l}\text { Random grouping } \\
\text { method }\end{array}$ & $\begin{array}{l}\text { Assigning } \\
\text { Hide }\end{array}$ & Blindness & $\begin{array}{l}\text { Case } \\
\text { shedding }\end{array}$ & $\begin{array}{l}\text { Pre-treatment baseline } \\
\text { comparison }\end{array}$ \\
\hline Yanjun Fu 2017 & Not mentioned & $\begin{array}{l}\text { Random number } \\
\text { table }\end{array}$ & Yes & $\begin{array}{l}\text { Not } \\
\text { mentioned }\end{array}$ & None & Yes \\
\hline Yue Han 2019 & Not mentioned & $\begin{array}{l}\text { Random number } \\
\text { table }\end{array}$ & Yes & $\begin{array}{l}\text { Not } \\
\text { mentioned }\end{array}$ & None & Yes \\
\hline $\begin{array}{l}\text { Gongyu Hu } \\
2015\end{array}$ & Not mentioned & $\begin{array}{l}\text { No specific } \\
\text { method }\end{array}$ & $\begin{array}{l}\text { Not } \\
\text { mentioned }\end{array}$ & $\begin{array}{l}\text { Not } \\
\text { mentioned }\end{array}$ & None & Yes \\
\hline $\begin{array}{l}\text { Chonghua } \\
\text { Jiang } 2012\end{array}$ & Not mentioned & $\begin{array}{l}\text { Random number } \\
\text { table }\end{array}$ & Yes & $\begin{array}{l}\text { Not } \\
\text { mentioned }\end{array}$ & None & Yes \\
\hline $\begin{array}{l}\text { Chanjuan Liu } \\
2018\end{array}$ & Not mentioned & $\begin{array}{l}\text { No specific } \\
\text { method }\end{array}$ & $\begin{array}{l}\text { Not } \\
\text { mentioned }\end{array}$ & $\begin{array}{l}\text { Not } \\
\text { mentioned }\end{array}$ & None & Yes \\
\hline $\begin{array}{l}\text { Chunhua Qin } \\
2013\end{array}$ & Not mentioned & $\begin{array}{l}\text { No specific } \\
\text { method }\end{array}$ & $\begin{array}{l}\text { Not } \\
\text { mentioned }\end{array}$ & $\begin{array}{l}\text { Not } \\
\text { mentioned }\end{array}$ & None & Yes \\
\hline Chao Shi 2018 & Not mentioned & $\begin{array}{l}\text { No specific } \\
\text { method }\end{array}$ & $\begin{array}{l}\text { Not } \\
\text { mentioned }\end{array}$ & $\begin{array}{l}\text { Not } \\
\text { mentioned }\end{array}$ & None & Yes \\
\hline $\begin{array}{l}\text { Xiaojing Sun } \\
2018\end{array}$ & Not mentioned & $\begin{array}{l}\text { Random number } \\
\text { table }\end{array}$ & Yes & $\begin{array}{l}\text { Not } \\
\text { mentioned }\end{array}$ & None & Yes \\
\hline $\begin{array}{l}\text { Zhen Wang } \\
2012\end{array}$ & Not mentioned & $\begin{array}{l}\text { No specific } \\
\text { method }\end{array}$ & $\begin{array}{l}\text { Not } \\
\text { mentioned }\end{array}$ & $\begin{array}{l}\text { Not } \\
\text { mentioned }\end{array}$ & None & Yes \\
\hline $\begin{array}{l}\text { Hongyun } \\
\text { Zhang } 2010\end{array}$ & Not mentioned & $\begin{array}{l}\text { Random number } \\
\text { table }\end{array}$ & Yes & $\begin{array}{l}\text { Not } \\
\text { mentioned }\end{array}$ & None & Yes \\
\hline Li Zhang 2010 & Not mentioned & $\begin{array}{l}\text { No specific } \\
\text { method }\end{array}$ & $\begin{array}{l}\text { Not } \\
\text { mentioned }\end{array}$ & $\begin{array}{l}\text { Not } \\
\text { mentioned }\end{array}$ & None & Yes \\
\hline $\begin{array}{l}\text { Yaping Zhou } \\
2010\end{array}$ & Not mentioned & $\begin{array}{l}\text { Random number } \\
\text { table }\end{array}$ & Yes & $\begin{array}{l}\text { Not } \\
\text { mentioned }\end{array}$ & None & Yes \\
\hline $\begin{array}{l}\text { Zhou Zhou } \\
2010\end{array}$ & Not mentioned & $\begin{array}{l}\text { No specific } \\
\text { method }\end{array}$ & $\begin{array}{l}\text { Not } \\
\text { mentioned }\end{array}$ & $\begin{array}{l}\text { Not } \\
\text { mentioned }\end{array}$ & None & Yes \\
\hline Min Zhou 2017 & Not mentioned & $\begin{array}{l}\text { Random number } \\
\text { table }\end{array}$ & Yes & $\begin{array}{l}\text { Not } \\
\text { mentioned }\end{array}$ & None & Yes \\
\hline
\end{tabular}

\subsection{Meta-analysis}

\subsubsection{Effective Rate}

There was low heterogeneity between studies $\left(P=0.91, I^{2}=0 \%\right)$ and the combined effect size of FE model was used for analysis, showing that the treatment efficiency was significantly higher with the use of Xuezhikang (OR=3.63, 95\% $\mathrm{Cl}[2.69,4.90], P<0.00001)$, detailed in Figure 3. The publication bias was analyzed on the row funnel plot with the effective rate. The shape of the funnel plot was consistent with the inverted funnel type with narrow upper and wide lower shape, but the loose lower part and the graph were all hollow dots, suggesting the existence of publication bias. More details are shown in Figure 4.

\subsubsection{TC}

All 14 studies reported data on TC with significant heterogeneity between studies $\left(P<0.00001,\left.\right|^{2}=95 \%\right)$. Using single study exclusion was not effective in reducing heterogeneity, while changing to subgroups with different statins was effective in reducing heterogeneity. Using MD as the effect size and combining effect sizes using the RE model, forest plot results showed that the addition of Xuezhikang all significantly reduced TC levels (MD $=-0.61,95 \% \mathrm{Cl}[-0.84,-0.39], P<0.00001)$, Figure 5 for details. 


\subsubsection{TG}

14 studies reported changes in TG with significant heterogeneity between studies $\left(P<0.00001, \mathrm{I}^{2}=88 \%\right)$. Subgrouping with statins reduced heterogeneity, and forest plot results using the RE model with MD as the effect size showed that: the addition of Xuezhikang all significantly reduced TG levels (MD=-0.30,95\% CI[-0.41,-0.19], $P<0.00001)$, as detailed in Figure 6 .

\subsubsection{LDLC}

11 studies $^{[17,20-21,23-30]}$ reported changes in LDLC levels, including 886 patients in the trial group and 884 patients in the control group, with significant heterogeneity between studies $\left(P<0.00001,1^{2}=86 \%\right)$ and Heterogeneity was reduced by statins subgroup. The forest plot results show that the overall analysis results $(\mathrm{MD}=-0.33,95 \% \mathrm{CI}[-0.46,-0.20], P<0.00001)$ supported that the addition of Xuezhikang was more effective in reducing LDLC levels. However, in the subgroups, there was a statistically significant difference between the results of Xuezhikang combined with statins and statins used alone in the atorvastatin group and fluvastatin group $(P<0.00001)$, while there was no statistically significant difference in the simvastatin group, as detailed in Figure 7.

\subsubsection{HDLC}

Changes in HDLC levels were reported in 13 studies $^{[17-21,23-30]}$, including 1176 patients in the trial group and 1174 patients in the control group, with significant heterogeneity between studies $\left(P<0.00001, I^{2}=96 \%\right)$. Heterogeneity was reduced by statins subgroup. With MD as the effect size, and using the RE model, the forest plot results show that the addition of Xuezhikang all significantly increased HDLC levels $(\mathrm{MD}=0.23,95 \% \mathrm{Cl}[0.12,0.35], P<0.00001)$, as detailed in Figure 8.

\subsubsection{Adverse Event}

8 studies $^{[17,19,21,23,25,27,28,30]}$ reported adverse events during and after the middle stage of the study, including bloating, nausea, vomiting and headache, with large heterogeneity between studies $\left(P=0.001, I^{2}=71 \%\right) .8$ studies were subclassified according to whether the number of cases was greater than 100 , then we find out the heterogeneity was low in both subgroups $\left(1^{2}=0 \%\right.$ in both $)$. With OR as effect value, combined effect size of RE model was used for analysis. The results of forest plot showed that adding Xuezhikang could significantly reduce the number of adverse events happening, as detailed in Figure 9.

\section{Discussion}

Blood lipids are the general term for cholesterol, triglycerides, and lipids in serum. Hyperlipidemia refers to plasma lipoprotein disorders. It is a metabolic disease, and its direct damage to the body is not obvious, and it generally does not have specific clinical discomfort symptoms ${ }^{[31]}$. Cholesterol is the total amount of cholesterol contained in various lipoproteins in the blood. It exists in the human body mainly in the form of free cholesterol and cholesteryl esters, and its level is related to the patient's age, gender, dietary habits and genetic factors, but its metabolic changes are relatively slow ${ }^{[32]}$ and is less valuable than LDL for risk assessment ${ }^{[33]}$ and prediction ${ }^{[34]}$ of atherosclerotic cardiovascular disease. Triglycerides are formed when the three hydroxyl groups in the glycerol molecule are esterified by fatty acids and, similar to cholesterol, their levels are influenced by both genetics and the environment. However, unlike cholesterol, the metabolism of triglycerides is more influenced by diet and time, and triglyceride measurements may vary considerably within a short period of time in the same individual with dietary changes ${ }^{[35]}$. There was a study ${ }^{[36]}$ suggested that elevated triglycerides are likely to have atherogenic effects by affecting the structure of lipoproteins, and that mild to moderate elevations in serum triglyceride levels may increase the risk of coronary heart disease in patients. LDL is the lipid core that makes up the atherosclerotic plaque and is also the initial and maintaining element of the chronic inflammatory response that is the pathological manifestation of atherosclerosis, so an increase in LDL is a major risk factor for the occurrence and development of atherosclerosis ${ }^{[37]}$. HDL is responsible for reverse cholesterol transport - transporting cholesterol from peripheral tissues to the liver for circulation or excretion in the form of bile acids, reducing cholesterol deposition in the vascular wall and acting as an antiatherosclerotic agent ${ }^{[38]}$.

Dyslipidemia, characterized by elevated LDL and cholesterol, is a noteworthy risk factor for atherosclerotic cardiovascular diseases(ASCVD). Other types of dyslipidemia, such as increased TG and decreased HDLC, are also associated with the development of ASCVD ${ }^{[39]}$. The ultimate treatment goal for dyslipidemia is to effectively reduce the risk of developing ASCVD ${ }^{[34]}$. In the 2016- 
edition of the Chinese Guidelines for the Prevention and Treatment of Dyslipidemia ${ }^{[40]}$, it is recommended that patients with dyslipidemia need to be assessed for residual risk of ASCVD. LDL and cholesterol levels can be independent predictors of the risk of ASCVD in individuals or groups of patients. Cholesterol accounts for $50 \%$ of LDL, and although the two levels are generally parallel, cholesterol is susceptible to $\mathrm{HDL}^{[41]}$, and LDL plays a central role in the development of ASCVD. So lowering LDL levels is the main target of intervention in the treatment of dyslipidemia in clinical practice.

Although there is no clear evidence to support that lower lipid levels are associated with a lower risk of ASCVD, nor is there evidence of a specific lipid threshold for ASCVD risk reduction, current medication guidelines in most countries, mainly in China, support the setting of lipid-lowering targets rather than minimizing lipid levels ${ }^{[42]}$. Apart from considerations of improving patient compliance and facilitating physician assessment of lipid-lowering efficacy, the main reasons are that lipid modulation is a long-term treatment and intensive use has a borderline effect - a significant increase in adverse drug reactions ${ }^{[43]}$, a doubling of the patient's financial burden, a small but modest increase in lipid-lowering benefit, and no reduction in all-cause mortality ${ }^{[4]}$.

Statins are clinically preferred and are Class I Recommendations and Class A Evidence in a variety of cardiovascular guidelines, including lovastatin, simvastatin, pravastatin, fluvastatin, atorvastatin, resuprastatin and pitavastatin. As inhibitors of HMG-COA reductase, statins inhibit cholesterol synthesis of the rate-limiting enzyme HMG-CoA reductase, reduce cholesterol synthesis and subsequently cells are upregulated to indicate LDL receptors, and accelerate serum LDL catabolism, while inhibiting very low-density lipoprotein synthesis, thereby regulating blood lipids to reduce coronary heart disease mortality ${ }^{[45]}$. A number of studies ${ }^{[46-49]}$ have demonstrated that while regular doses of statins have a significant benefit in primary prevention in patients at high cardiovascular risk, further studies are needed to investigate the benefit in patients at low and intermediate risk. Similarly, there is no evidence to support that the benefits of intensive treatment with statins outweigh the risks, including (1) the benefits of short-term intensive intervention in the perioperative period in cardiovascular patients; (2) the benefits of long-term intensive intervention in patients with dyslipidemia-the proportional reduction in TC and LDLC, and the incidence of cardiovascular events and all-cause mortality; (3) the cost of medication to patients doubling may lead to reduced compliance; and (4) a significant increase in adverse reactions, predominantly abnormal liver function, but also including myalgia, headache, insomnia and various gastrointestinal symptoms. How are statin adverse reactions alleviated? Guidelines suggest switching to another statin, reducing dosage, decreasing the frequency of dosing or discontinuing the statin, but the latter three management options not only reduce the benefits of lipid modulation but may increase the risk of cardiovascular events.

Xuezhikang, the only natural lipid regulator recognized by several authoritative guidelines in the cardiovascular field [including: ACC, AHA 2013 Guidelines for the Treatment of Blood Cholesterol to Reduce the Risk of Atherosclerosis in Adults, ESC, EAS 2011, 2016 Guidelines for the Management of Dyslipidemia, China 2007 Guidelines for the Diagnosis and Prevention of Chronic Stable Angina, 2016 Guidelines for the Prevention and Treatment of Dyslipidemia in Adults, 2018 Guidelines for the Rational Use of Drugs in Coronary Heart Disease. Guidelines, 2018 Guidelines for the Diagnosis and Treatment of Stable Coronary Heart Disease, 2018 Guidelines for the Diagnosis and Treatment of Acute Myocardial Infarction with Chinese and Western Medicine] is recognized as a natural lipid-regulating drug. Its main ingredient is monascus - which has been used for centuries in China as a food colouring and flavour enhancer ${ }^{[50]}$. It is refined through a modern GMP-standard process by adding special monascus to rice fermentation. It has a mechanism similar to that of statins, with 13 natural statin complexes as the main ingredients ${ }^{[51]}$. It is unique in reducing the risk of adverse reactions associated with the use of a single statin ${ }^{[52]}$. A number of RCTs ${ }^{[53-60]}$ have demonstrated that Xuezhikang can lower cholesterol and LDL levels, reduce the incidence of adverse events, reduce the risk of cardiovascular events and recurrence, and significantly reduce coronary heart disease mortality and all-cause mortality. It is also inexpensive compared to synthetic statins. Based on the original lipid-lowering treatment with synthetic statins, the addition of Xuezhikang can be equivalent to intensify the effective of statin treatment and mitigate the risk of adverse reactions.

To investigate the benefits and risks of intensifying statin therapy with Xuezhikang, this study included 2042 patients in 14 RCTs, with 1022 patients in the trial group (statin plus Xuezhikang) and 1020 patients in the control group (statin alone), and conducted a metaanalysis of the combined effect sizes of efficiency, TC, TG, LDLC, HDLC and adverse events. The results showed that compared with statins used alone, the addition of Xuezhikang intensive treatment could (i) significantly increase the effective rate, (ii) more effectively reduce TC, TG and LDLC levels and increase HDLC levels, (iii) significantly reduce the incidence of adverse events, and (iv) the lipid-regulating effect of simvastatin combined with Xuezhikang on LDLC was not significant. 
The 14 RCTs included in this study were low to moderate quality studies with obvious limitations, including: 1. All studies did not specify sample size estimates, which may affect test validity; 2 . Although all included studies indicated that cases were randomly assigned to two groups, only eight studies clearly indicated the randomization method they used, while the remaining studies did not mention the specific randomization method and allocation concealment method, which is subject to unknowable selectivity bias. The remaining studies did not mention the specific randomization method and allocation concealment method, resulting in unknowable selectivity bias; 3 . All cases did not mention whether they were blinded, either blinding of investigators and subjects or blinded evaluation of study outcomes, resulting in unknowable implementation bias and measurement bias; 4 . Funnel plots of efficiency rates were found to be consistent with an inverted funnel shape with a narrow top and a wide bottom, but the lower part of the graph was lax and there are all hollow dots in the graphs, suggesting that there are insufficient large sample studies, low sample quality and publication bias; 5 . Only 8 studies fully reported adverse events during the study period and follow-up, resulting in follow-up bias, Moreover, none of the three major systemic adverse reactions of statins - liver, muscle and digestive system - have been tracked and reported, which is not highly targeted; 6 . In the study design, the effective rate of all studies took the proportion of cholesterol reduction as the threshold. TC and LDLC were equally important in lipid-regulating therapy, but only 11 RCTS reported LDLC levels; TG was reported in each RCTS. Since TG is easily affected by diet, only 10 RCTS mentioned whether to add therapeutic dietary intervention, which would cause unknown bias in this study.

In summary, for the RCT study with statins combined with Xuezhikang as the intervention in the trial group, this analysis recommends: 1 . The RCT should be designed more precisely before starting the study, for example, sample size estimation, clear randomization method, clear allocation method, application of blinding, and the number of adverse reactions and case shedding in the trial should be recorded based on facts; 2 . Large sample clinical trials can be conducted to provide more comprehensive and objective clinical treatment; 3 . The design of outcome indicators of the study should (1) if lipid-regulating efficacy is the study objective, the magnitude of lipid regulation of TC and LDLC should be the primary outcome indicator, and TG, HLDL and other lipoproteins should be secondary outcome indicators; (2) if safety is the study objective, the reporting of adverse effects should include liver, muscle and digestive system; (3) if TG is reported, whether to include dietary control should be considered.

In Conclusion, the information extracted from the 14 RCTs included in this study was systematically evaluated and the results showed that Xuezhikang combined with statins had better and more stable modulation of cholesterol, triglyceride and LDL levels than statins used alone in terms of regulation of lipids in patients with hyperlipidemia, and there is a lower incidence rate of adverse events. The RCTs included in this study were of low to moderate quality and more high quality RCTs with large samples are needed to provide more reliable evidence.

\section{Abbreviations}

Xuezhikang capsule: Xuezhikang; total cholesterol: TC; triglycerides: TG; low density lipoprotein: LDLC; high density lipoprotein: HDLC; Randomized controlled trial: RCT; odds ratio (OR); mean difference: $\mathrm{MD}$; confidence intervals: $\mathrm{Cl}$; fixed effects model: FE; randomeffects model: RE; standard error: SE; atherosclerotic cardiovascular diseases: ASCVD

\section{Declarations}

\section{FUNDING}

The authors did not receive support from any organization for the submitted work.

\section{DISCLOSURES}

All authors certify that they have no affiliations with or involvement in any organization or entity with any financial interest or nonfinancial interest in the subject matter or materials discussed in this manuscript.

\section{ACKNOWLEDGMENTS}

All authors acknowledge the full responsibility for the analyses and interpretation of the report.

\section{AVAILABILITY OF DATA AND MATERIALS}


All data generated or analysed during this study are included in this published article [and its supplementary information files].

\section{AUTHOR CONTRIBUTIONS}

Chen DX and Feng HY contributed to literature search, data extraction, and data analysis. Li YG contributed to study conception and data analysis. Feng HY and Huang JZ contributed to study conception, manuscript drafting, and data analysis. Chen DX critically revised the manuscript. All authors acknowledge the full responsibility for the analyses and interpretation of the report.

\section{References}

1. Libby P, Buring JE, Badimon L, Hansson GK, Deanfield J, Bittencourt MS, Tokgözoğlu L, Lewis EF. Atherosclerosis. Nat Rev Dis Primers. 2019 Aug 16;5(1):56. doi: 10.1038/s41572-019-0106-z. PMID: 31420554.

2. Stewart J, McCallin T, Martinez J, Chacko S, Yusuf S. Hyperlipidemia. Pediatr Rev. 2020 Aug;41(8):393-402. doi: 10.1542/pir.2019-0053. PMID: 32737252.

3. Grundy SM, Stone NJ, Bailey AL, Beam C, Birtcher KK, Blumenthal RS, Braun LT, de Ferranti S, Faiella-Tommasino J, Forman DE, Goldberg R, Heidenreich PA, Hlatky MA, Jones DW, Lloyd-Jones D, Lopez-Pajares N, Ndumele CE, Orringer CE, Peralta CA, Saseen JJ, Smith SC Jr, Sperling L, Virani SS, Yeboah J. 2018 AHA/ACC/AACVPR/AAPA/ABC/ACPM/ADA/AGS/APhA/ASPC/NLA/PCNA Guideline on the Management of Blood Cholesterol: A Report of the American College of Cardiology/American Heart Association Task Force on Clinical Practice Guidelines. Circulation. 2019 Jun 18;139(25):e1082-e1143. doi: 10.1161/CIR.0000000000000625. Epub 2018 Nov 10. Erratum in: Circulation. 2019 Jun 18;139(25):e1182-e1186. PMID: 30586774; PMCID: PMC7403606.

4. Robinson JG. Overview of the 2013 ACC/AHA Guideline on the Treatment of Blood Cholesterol to Reduce Atherosclerotic Cardiovascular Risk in Adults. Future Cardiol. 2014 Mar;10(2):149-52. doi: 10.2217/fca.14.8. PMID: 24762237.

5. de Keyser CE, Leening MJ, Romio SA, Jukema JW, Hofman A, Ikram MA, Franco OH, Stijnen T, Stricker BH. Comparing a marginal structural model with a Cox proportional hazard model to estimate the effect of time-dependent drug use in observational studies: statin use for primary prevention of cardiovascular disease as an example from the Rotterdam Study. Eur J Epidemiol. 2014 Nov;29(11):841-50. doi: 10.1007/s10654-014-9951-y. Epub 2014 Sep 12. PMID: 25213404.

6. Abd TT, Jacobson TA. Statin-induced myopathy: a review and update. Expert Opin Drug Saf. 2011 May;10(3):373-87. doi:10.1517/14740338.2011.540568. Epub 2011 Feb 23. PMID: 21342078.

7. Zhao W, Xiao ZJ, Zhao SP. The Benefits and Risks of Statin Therapy in Ischemic Stroke: A Review of the Literature. Neurol India. 2019 Jul-Aug;67(4):983-992. doi: 10.4103/0028-3886.266274. PMID: 31512619.

8. Šimić I, Reiner Ž. Adverse effects of statins - myths and reality. Curr Pharm Des. 2015;21(9):1220-6. doi: 10.2174/1381612820666141013134447. PMID: 25312733.

9. Chu S, Hu L, Wang X, Sun S, Zhang T, Sun Z, Shen L, Jin S, He B. Xuezhikang ameliorates contrast media-induced nephropathy in rats via suppression of oxidative stress, inflammatory responses and apoptosis. Ren Fail. 2016 Nov;38(10):1717-25. doi: 10.1080/0886022X.2016.1207052. Epub 2016 Nov 1. PMID: 27800691.

10. Gao Y, Chen X, Li C, Wang H, Tian J, Fu F. Toxicological evaluation of, red rice yeast extract, Xuezhikang: Acute, 26-week chronic and genotoxicity studies. Regul Toxicol Pharmacol. 2020 Jul;114:104654. doi:10.1016/j.yrtph.2020.104654. Epub 2020 Apr 9. PMID: 32278069.

11. Committee of Cardio-Cerebro-Vascular Diseases of Gerontological Society of China; Working Group of Chinese Expert Consensus on the Use of Xuezhikang. [Chinese expert consensus on the use of Xuezhikang (2017 revised edition)]. Zhonghua Nei Ke Za Zhi. 2018 Feb 1;57(2):97-100. Chinese. doi: 10.3760/cma.j.issn.0578-1426.2018.02.003. PMID: 29397593.

12. Feng D, Ge C, Tan ZY, Sun JG, Xie Y, Yao L, Yan CX, Aa JY, Wang GJ. Isoflavones enhance pharmacokinetic exposure of active lovastatin acid via the upregulation of carboxylesterase in high-fat diet mice after oral administration of Xuezhikang capsules. Acta Pharmacol Sin. 2018 Nov;39(11):1804-15. doi:10.1038/s41401-018-0039-1. Epub 2018 Jun 19. PMID: 29921884; PMCID: PMC6289385.

13. Lu Z, Kou W, Du B, Wu Y, Zhao S, Brusco OA, Morgan JM, Capuzzi DM, Chinese Coronary Secondary Prevention Study Group, Li S. Effect of Xuezhikang, an extract from red. yeast Chinese rice, on coronary events in a Chinese population with previous myocardial infarction. Am J Cardiol. 2008 Jun 15;101(12):1689-93. doi: 10.1016/j.amjcard.2008.02.056. Epub 2008 Apr 11. PMID: 18549841. 
14. Liberati A, Altman DG, Tetzlaff J, Mulrow C, Gøtzsche PC, loannidis JP, Clarke M, Devereaux PJ, Kleijnen J, Moher D. The PRISMA statement for reporting systematic reviews and meta-analyses of studies that evaluate health care interventions: explanation and elaboration. J Clin Epidemiol. 2009 Oct;62(10):e1-34. doi:10.1016/j.jclinepi.2009.06.006. Epub 2009 Jul 23. PMID: 19631507.

15. Cumpston M, Li T, Page MJ, Chandler J, Welch VA, Higgins JP, Thomas J. Updated guidance for trusted systematic reviews: a new edition of the Cochrane Handbook for Systematic Reviews of Interventions. Cochrane Database Syst Rev. 2019 Oct 3;10:ED000142. doi: 10.1002/14651858.ED000142. PMID: 31643080.

16. Preuß M, Ziegler A. A simplification and implementation of random-effects meta-analyses based on the exact distribution of Cochran's Q. Methods Inf Med. 2014;53(1):54-61. doi:10.3414/ME13-01-0073. Epub 2013 Dec 9. PMID: 24317521.

17. Fu Yanjun.Observation on the effect of blood lipid Kang capsule combined with atorvastatin calcium in the treatment of hyperlipidemia[J]. China Rural Medicine,2017,24(24):52-53.doi:10.19542/j.cnki. 1006-5180.001192.

18. Han Yue. Study on the modulating effect of Rosuvastatin combined with Blood Lipocon on hyperlipidemia in the elderly[J]. Family Medicine,2019,(12):148-149.http://www.wanfangdata.com.cn/details/detail.do?_type=perio\&id=jtyy201912103.

19. Hu, GangYu. Clinical efficacy of blood lipid kang combined with atorvastatin in the treatment of hyperlipidemia[J]. Chinese primary care medicine,2015,22(06):921-923.doi:CNKI:SUN:ZJCY.0.2015-06-046.

20. Jiang ZongHua,Chen YongQing. Clinical efficacy of blood lipid kang capsule combined with simvastatin in the treatment of hyperlipidemia[J]. Strait Pharmacology. 2012;24(11):140-1. ..doi:CNKI:SUN:HAIX.0.2012-11-076..

21. Liu Chanjuan $\mathrm{Xu}$, Wenshen $\mathrm{W}$, Jing. A study on the effect of atorvastatin calcium tablets and blood lipidcon in the treatment of hyperlipidemia[J]. China Medical Case,2018,19(10):92-94.doi:CNKI:SUN:ZGBN.0.2018-10-033.

22. Qin Chunhong,Fu Yezhou. Analysis of the efficacy of combined Chinese and Western medicine in the treatment of hyperlipidemia[J]. Clinical Research in Chinese Medicine,2013,5(19):63-64.doi:CNKI:SUN:ZYLY.0.2013-19-037.

23. Shi Chao,Wang Xing,Zhu Hongling. Clinical observation on the treatment of hyperlipidemia with blood lipid kang capsule combined with fluvastatin sodium[J]. World Clinical Drugs,2018,39(01):43-46+4.doi:10.13683/j.wph.2018.01.009.

24. Sun Xiaojing,Liu Xiaoyong,He Shimin. Lipid-regulating effect of blood lipid kang capsule combined with simvastatin and the effect on 24-h urinary albumin excretion and plasma endothelin-1 level[J]. Drug Evaluation Research,2018,41(06):10941097.doi:CNKI:SUN:YWPJ.0.2018-06-029.

25. Wang Z. Efficacy of blood lipid kang combined with atorvastatin in the treatment of diabetic hyperlipidemia[J]. Chinese and foreign medical research,2012,10(21):16-17.doi:10.14033/j.cnki.cfmr.2012.21.070.

26. Zhang $\mathrm{H}$. Analysis of the efficacy of fluvastatin in combination with blood lipidcon in the treatment of coronary heart disease[J]. China Practical Medicine. 2010;5(22):115-6. doi:10.14163/j.cnki.11-5547/r.2010.22.095.

27. Zhang, Li,Tang Maoqing. Clinical observation on the treatment of hyperlipidemia with simvastatin and blood lipid kang[J]. Journal of Sichuan North Medical College,2010,25(06):548-550.doi:CNKI:SUN:NOTH.0.2010-06-013.

28. Zhou Yaping S. Luoying. Efficacy of blood lipid kang and simvastatin in the treatment of hyperlipidemia in type 2 diabetes mellitus[J]. Zhejiang Journal of Integrative Medicine,2010,20(06):356-357.doi:CNKI:SUN:ZJZH.0.2010-06-015.

29. Zhou Z. Clinical observation of 39 cases of hyperlipidemia treated with combined traditional Chinese and Western medicine[J]. Chinese Medicine.Herald,2010,16(04):17-19.doi:10.13862/j.cnki.cn43-1446/r.2010.04.059.

30. Zou M. Efficacy of blood lipid kang capsules combined with atorvastatin in the treatment of hyperlipidemia and the effect on blood lipids and inflammatory factors[J]. World Traditional Chinese Medicine,2017,12(08):1824-1827.doi:10.3969/j.issn.16737202.2017.08.025.

31. Yu JN, Cunningham JA, Thouin SR, Gurvich T, Liu D. Hyperlipidemia. Prim Care. 2000 Sep;27(3):541-87,v. doi: 10.1016/s00954543(05)70164-0. PMID: 10918670.

32. Luo J, Yang H, Song BL. Mechanisms and regulation of cholesterol homeostasis. Nat Rev Mol Cell Biol. 2020 Apr;21(4):225-45. doi:10.1038/s41580-019-0190-7. Epub 2019 Dec 17. PMID: 31848472.

33. Soliman GA. Dietary Cholesterol and the Lack of Evidence in Cardiovascular Disease. Nutrients. 2018 Jun 16;10(6):780. doi: 10.3390/nu10060780. PMID: 29914176; PMCID: PMC6024687.

34. Chinese adult dyslipidemia prevention guide [J]. Chinese journal of cardiovascular disease. 2007;35(5):390-419. The doi: CNKI: SUN: ZHXX. 0.2007-05-002. 
35. Kolovou G, Anagnostopoulou K, Mikhailidis DP. One century of triglycerides, but there is still lots to learn! Curr Drug Targets. 2009 Apr;10(4):299-301. doi: 10.2174/138945009787846461. Erratum in: Curr Drug Targets. 2009 Jun;10(6):578. PMID: 19355854.

36. Tziomalos K, Athyros VG, Karagiannis A, Kolovou GD, Mikhailidis DP. Triglycerides and vascular risk: insights from epidemiological data and interventional studies. Curr Drug Targets. 2009 Apr;10(4):320-7. doi: 10.2174/138945009787846425. PMID: 19355856.

37. Khatana C, Saini NK, Chakrabarti S, Saini V, Sharma A, Saini RV, Saini AK. Mechanistic Insights into the Oxidized Low-Density Lipoprotein-Induced Atherosclerosis. Oxid Med Cell Longev. 2020 Sep 15;2020:5245308. doi: 10.1155/2020/5245308. PMID: 33014272; PMCID: PMC7512065.

38. Francis GA. The complexity of HDL. Biochim Biophys Acta. 2010 Dec;1801(12):1286-93. doi:10.1016/j.bbalip.2010.08.009. Epub 2010 Aug 21. PMID: 20736082.

39. Falk E. Pathogenesis of atherosclerosis. J Am Coll Cardiol. 2006 Apr 18;47(8 Suppl):C7-12. doi: 10.1016/j.jacc.2005.09.068. PMID: 16631513.

40. Zhu JR, Gao RL, Zhao SP, Lu GP, Zhao D, Li JJ. Chinese adult dyslipidemia prevention guide (2016 edition) [J]. Chinese journal of cardiovascular disease. 2016;44(10):833-53. The doi: CNKI: SUN: ZHXX. 0.2016-10-008.

41. Malle E, Marsche G, Panzenboeck U, Sattler W. Myeloperoxidase-mediated oxidation of high-density lipoproteins: fingerprints of newly recognized potential proatherogenic lipoproteins. Arch Biochem Biophys. 2006 Jan 15;445(2):245-55. doi: 10.1016/j.abb.2005.08.008. Epub 2005 Aug 31. PMID: 16171772.

42. Coronary heart disease (CHD) and reasonable medication guide (2nd edition) [J]. Chinese journal of medical frontier (electronic). 2018, 10 (6): 1-130 doi: CNKI: SUN: YXQY. 0.2018-06-001.

43. Rabar S, Harker M, O'Flynn N, Wierzbicki AS. Guideline Development Group. Lipid modification and cardiovascular risk assessment for the primary and secondary prevention of cardiovascular disease: summary of updated NICE guidance. BMJ. 2014 Jul 17;349:g4356. doi: 10.1136/bmj.g4356. PMID: 25035388.

44. Grassroots cardiovascular disease integrated management practice guidelines 2020 [J]. Chinese journal of medical frontier (electronic). 2020, 12 (08): 1-73 doi: CNKI: SUN: YXQY. 0.2020-08-002.

45. Sirtori CR. The pharmacology of statins. Pharmacol Res. 2014 Oct;88:3-11. doi:10.1016/j.phrs.2014.03.002. Epub 2014 Mar 20. PMID: 24657242.

46. Dai W, Huang XS, Zhao SP. No evidence to support high-intensity statin in Chinese patients with coronary heart disease. Int J Cardiol. 2016 Feb 1;204:57-8. doi: 10.1016/j.ijcard.2015.11.164. Epub 2015 Nov 23. PMID: 26655539.

47. HPS2-THRIVE Collaborative Group. HPS2-THRIVE randomized placebo-controlled trial in 25673 high-risk patients of ER niacin/laropiprant: trial design, pre-specified muscle and liver outcomes, and reasons for stopping study treatment. Eur Heart J. May 2013;34:1279-91. https://doi.org/10.1093/eurheartj/eht055. Issue 17, 1 .

48. Wang XN, Wang F, Ye P, Hu DY, Zhao SP, Wang YJ, Mu YM, Yan XW, Li ZQ, Wei YD. [Cross sectional study of familial hypercholesterolemia in dyslipidemia patients receiving lipid-lowering therapy: DYSIS-China subgroup analysis]. Zhonghua Xin Xue Guan Bing Za Zhi. 2021 Jun 24;49(6):564-571. Chinese. doi: 10.3760/cma.j.cn112148-20201118-00918. PMID: 34126723.

49. Zhao SP, Peng DQ, Yu BL, Huo Y; CHILLAS investigators. Rationale and design of China intensive lipid lowering with statins in acute coronary syndrome: the CHILLAS study. Am Heart J. 2009 Oct;158(4):509-512.e1. doi: 10.1016/j.ahj.2009.07.030. PMID: 19781407.

50. Li JJ, Lu ZL, Kou WR, Chen Z, Wu YF, Yu XH, Zhao YC. Chinese Coronary Secondary Prevention Study Group. Impact of Xuezhikang on coronary events in hypertensive patients with previous myocardial infarction from the China Coronary Secondary Prevention Study (CCSPS). Ann Med. 2010 Apr;42(3):231-40. doi: 10.3109/07853891003652534. PMID: 20350253.

51. Zhao SP, Liu L, Cheng YC, Shishehbor MH, Liu MH, Peng DQ, Li YL. Xuezhikang, an extract of cholestin, protects endothelial function through antiinflammatory and lipid-lowering mechanisms in patients with coronary heart disease. Circulation. 2004 Aug 24;110(8):915-20. doi: 10.1161/01.CIR.0000139985.81163.CE. Epub 2004 Aug 16. PMID: 15313947.

52. Feng $\mathrm{Y}, \mathrm{Xu} \mathrm{H}$, Chen K. Natural polypill Xuezhikang: its clinical benefit and potential multicomponent synergistic mechanisms of action in cardiovascular disease and other chronic conditions. J Altern Complement Med. 2012 Apr;18(4):318-28. doi: 10.1089/acm.2011.0187. Epub 2012 Apr 10. PMID: 22489805.

53. Zhao SP, Lu ZL, Du BM, Chen Z, Wu YF, Yu XH, Zhao YC, Liu L, Ye HJ, Wu ZH. China Coronary Secondary Prevention Study (CCSPS). Xuezhikang, an extract of cholestin, reduces cardiovascular events in type 2 diabetes patients with coronary heart

Page $12 / 20$ 
disease: subgroup analysis of patients with type 2 diabetes from China coronary secondary prevention study (CCSPS). J Cardiovasc Pharmacol. 2007 Feb;49(2):81-4. doi: 10.1097/FJC.0b013e31802d3a58. PMID: 17312447.

54. Li JJ, Lu ZL, Kou WR, Chen Z, Wu YF, Yu XH, Zhao YC. Chinese Coronary Secondary Prevention Study Group. Beneficial impact of Xuezhikang on cardiovascular events and mortality in elderly hypertensive patients with previous myocardial infarction from the China Coronary Secondary Prevention Study (CCSPS). J Clin Pharmacol. 2009 Aug;49(8):947-56. doi:

10.1177/0091270009337509. PMID: 19602720.

55. Li JJ, Hu SS, Fang CH, Hui RT, Miao LF, Yang YJ, Gao RL. Effects of xuezhikang, an extract of cholestin, on lipid profile and Creactive protein: a short-term time course study in patients with stable angina. Clin Chim Acta. 2005 Feb;352(1-2):217-24. doi: 10.1016/j.cccn.2004.09.026. PMID: 15653117.

56. Li JJ, Wang Y, Nie SP, Li Q, Li YS, Huang Y, Hui RT. Xuezhikang, an extract of cholestin, decreases plasma inflammatory markers and endothelin-1, improve exercise-induced ischemia and subjective feelings in patients with cardiac syndrome X. Int J Cardiol. 2007 Oct 31;122(1):82-4. doi: 10.1016/j.ijcard.2006.11.031. Epub 2006 Dec 28. PMID: 17196275.

57. Ye P, Lu ZL, Du BM, Chen Z, Wu YF, Yu XH, Zhao YC. CCSPS Investigators. Effect of xuezhikang on cardiovascular events and mortality in elderly patients with a history of myocardial infarction: a subgroup analysis of elderly subjects from the China Coronary Secondary Prevention Study. J Am Geriatr Soc. 2007 Jul;55(7):1015-22. doi: 10.1111/j.1532-5415.2007.01230.x. PMID: 17608873.

58. DU BM, Lu ZL, Chen Z, Wu YF. [The beneficial effects of lipid-lowering therapy with xuezhikang on cardiac events and total mortality in coronary heart disease patients with or without hypertension: a random, double-blinded, placebo controlled clinical trial]. Zhonghua Xin Xue Guan Bing Za Zhi. 2006 Oct;34(10):890-4. Chinese. PMID: 17217713.

59. Li JJ, Lu ZL, Kou WR, Bolli R, Chen Z, Wu YF, Yu XH, Zhao YC. Impact of long-term Xuezhikang therapy on cardiovascular events in high-risk patients with nonspecific, preexisting abnormal liver tests: a post-hoc analysis from Chinese Coronary Secondary Prevention Study (CCSPS). Int J Cardiol. 2012 Feb 9;154(3):362-5. doi: 10.1016/j.ijcard.2011.11.005. Epub 2011 Dec 1. PMID: 22133469.

60. Liu ZQ, Cui LQ, Wang Y. [Effect of Xuezhikang on cardiac function, serum C-reactive protein and blood lipid in patients with chronic heart failure]. Zhongguo Zhong Xi Yi Jie He Za Zhi. 2007 Mar;27(3):220-2. Chinese. PMID: 17432681.

\section{Figures}




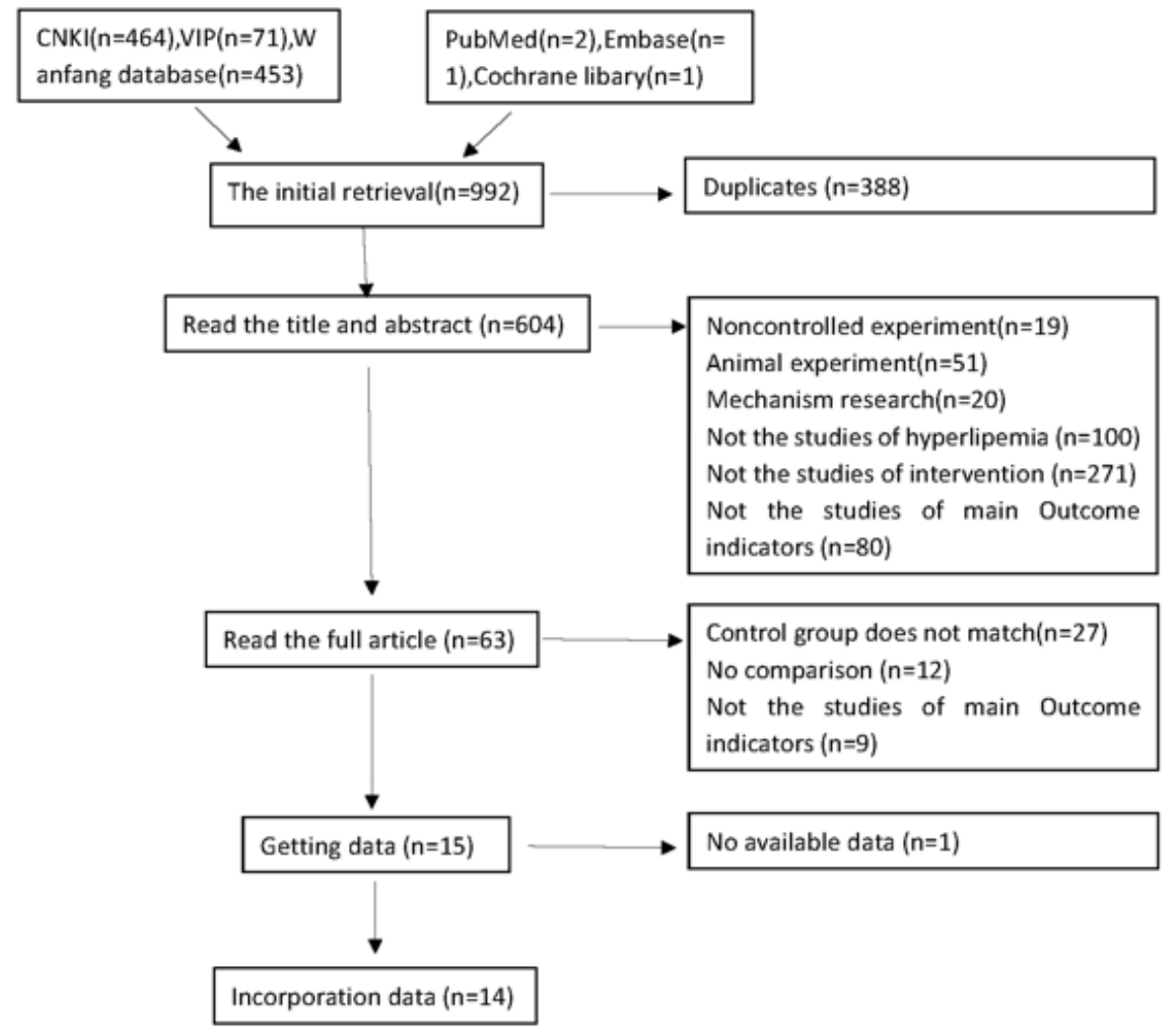

\section{Figure 1}

Flow diagram of the study selection process

\section{Random sequence generation (selection bias)}

Allocation concealment (selection bias)

Blinding of participants and personnel (performance bias)

Blinding of outcome assessment (detection bias)

Incomplete outcome data (attrition bias)

Selective reporting (reporting bias)

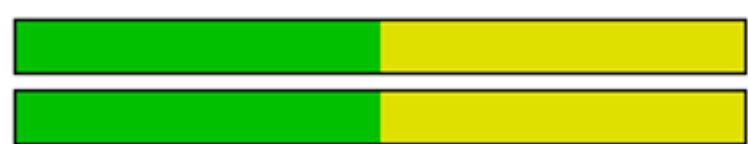

$$
\text { L }
$$

Other bias
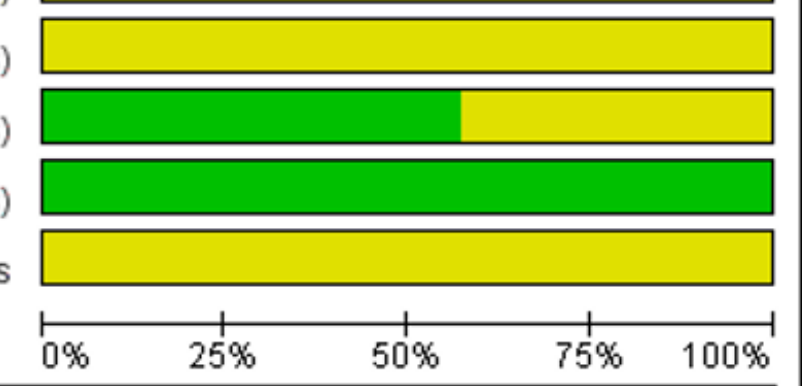

\begin{tabular}{|ll|}
\hline Low risk of bias $\quad \square$ Unclear risk of bias $\quad \square$ High risk of bias \\
\hline
\end{tabular}

\section{Figure 2}

Risk of bias graph: review authors' judgements about each risk of bias item presented as percentages across all included studies. 
Experimental Control Odds Ratio

Study or Subgroup

Chanjuan Liu 2018

Chao Shi 2018

Chonghua Jiang 2012

Chunhong Qin 2013

Gangyu Hu 2015

Hongyun Zhang 2010

Li Zhang 2010

Min Zhou 2017

Xiaojing Sun 2018

Yanjun Fu 2017

Yaping Zhou 2010

Yue Han 2019

Zhen Wang 2012

Zhou Zhou 2010

Total $(95 \% \mathrm{Cl})$

Total events

Heterogeneity: $\mathrm{Chi}^{2}=6.77, \mathrm{df}=13(\mathrm{P}=0.91) ; \mathrm{I}^{2}=0 \%$

Test for overall effect: $Z=8.29$ ( $P<0.00001)$
Odds Ratio

M-H, Fixed, 95\% Cl

$\begin{array}{llllll}50 & 52 & 44 & 52 & 3.5 \% & 4.55[0.92,22.55]\end{array}$

$\begin{array}{llllll}53 & 62 & 43 & 62 & 12.7 \% & 2.60[1.07,6.33]\end{array}$

$\begin{array}{llllll}50 & 52 & 44 & 52 & 3.5 \% & 4.55[0.92,22.55]\end{array}$

$\begin{array}{llllll}37 & 40 & 34 & 40 & 5.2 \% & 2.18[0.50,9.39]\end{array}$

$\begin{array}{llllll}45 & 60 & 34 & 60 & 17.3 \% & 2.29[1.06,4.98]\end{array}$

$\begin{array}{llllll}27 & 30 & 23 & 30 & 4.7 \% & 2.74[0.63,11.82]\end{array}$

$\begin{array}{llllll}179 & 182 & 157 & 180 & 5.3 \% & 8.74[2.58,29.67]\end{array}$

$\begin{array}{llllll}233 & 244 & 203 & 244 & 18.7 \% & 4.28[2.14,8.54]\end{array}$

$\begin{array}{llllll}45 & 48 & 37 & 48 & 4.7 \% & 4.46[1.16,17.18]\end{array}$

$\begin{array}{llllll}70 & 75 & 61 & 75 & 8.3 \% & 3.21[1.09,9.44]\end{array}$

$\begin{array}{llllll}26 & 30 & 24 & 30 & 6.5 \% & 1.63[0.41,6.47]\end{array}$

$\begin{array}{llllll}34 & 36 & 28 & 36 & 3.2 \% & 4.86[0.95,24.75]\end{array}$

$\begin{array}{llllll}37 & 39 & 30 & 39 & 3.1 \% & 5.55[1.11,27.66]\end{array}$

$\left.\begin{array}{llllll}37 & 39 & 31 & 39 & 3.2 \% & 4.77\end{array}\right]$

$989 \quad 987 \quad 100.0 \% \quad 3.62[2.67,4.90]$

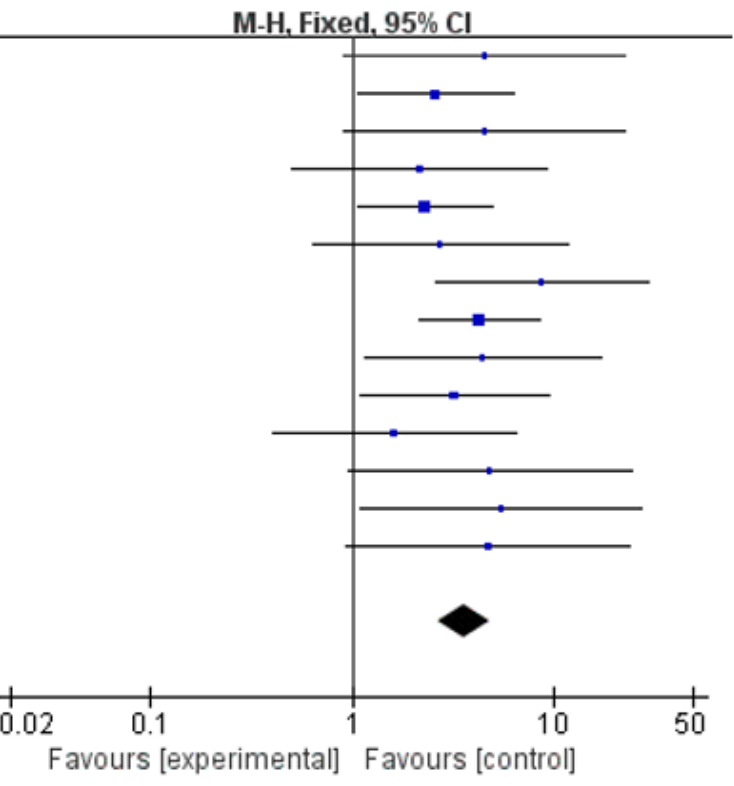

\section{Figure 3}

Comparison of effective rate between statin in combination with Xuezhikang and statin only in in all observation studies.

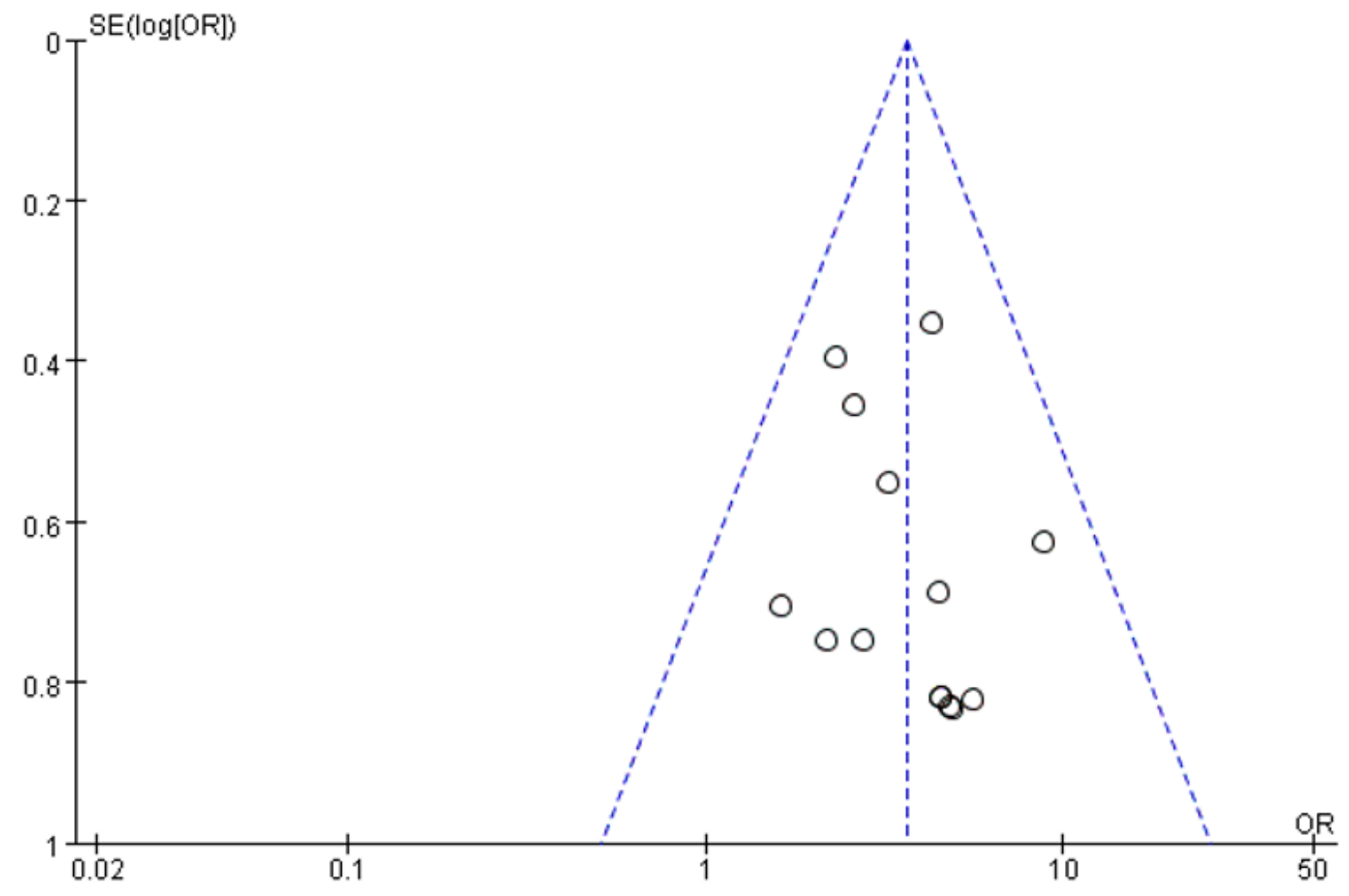

\section{Figure 4}

The funnel plot for all observation studies in the meta-analysis. 


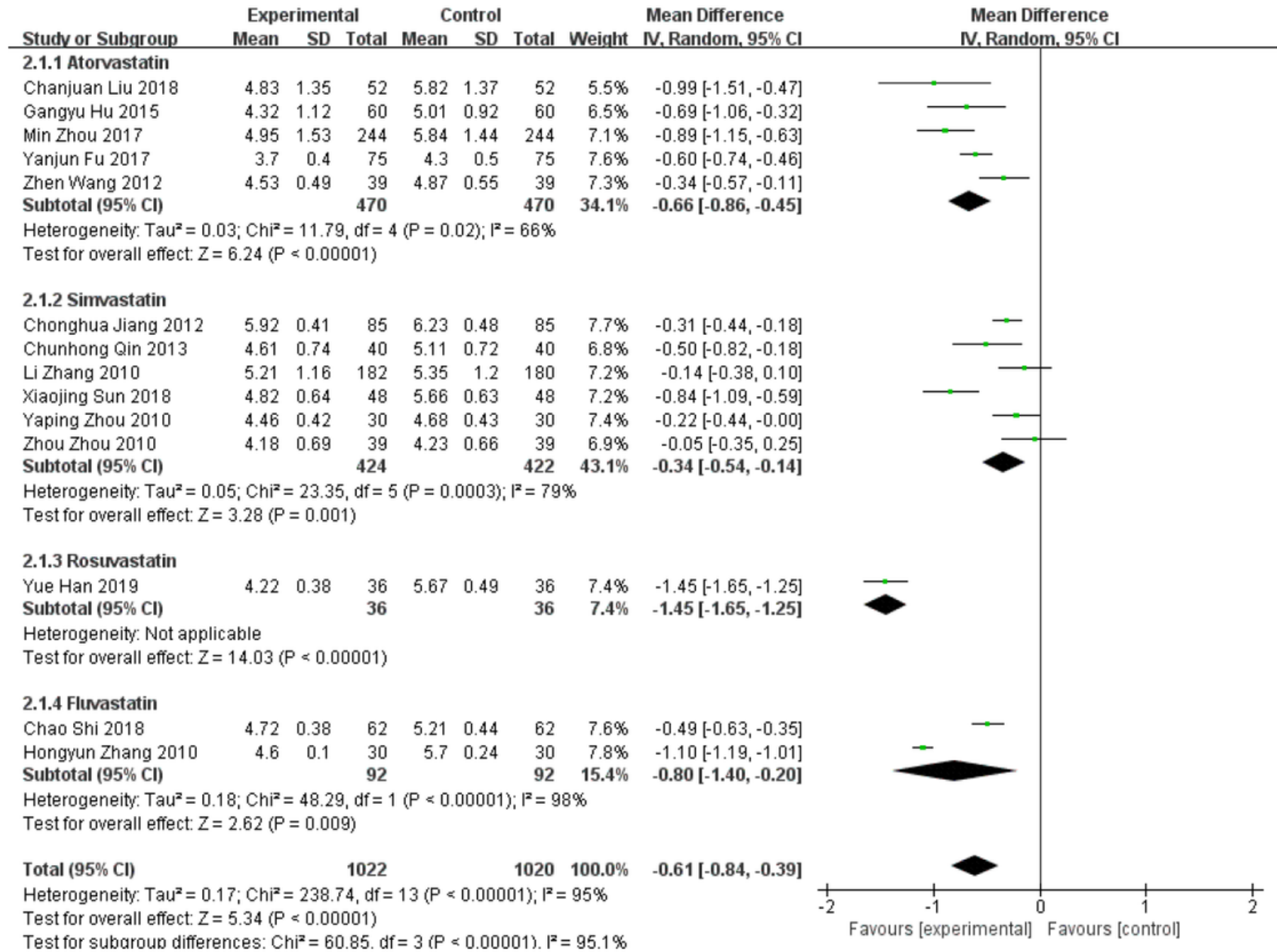

Figure 5

Comparison of TC between statin in combination with Xuezhikang and statin only in all eligible studies. 


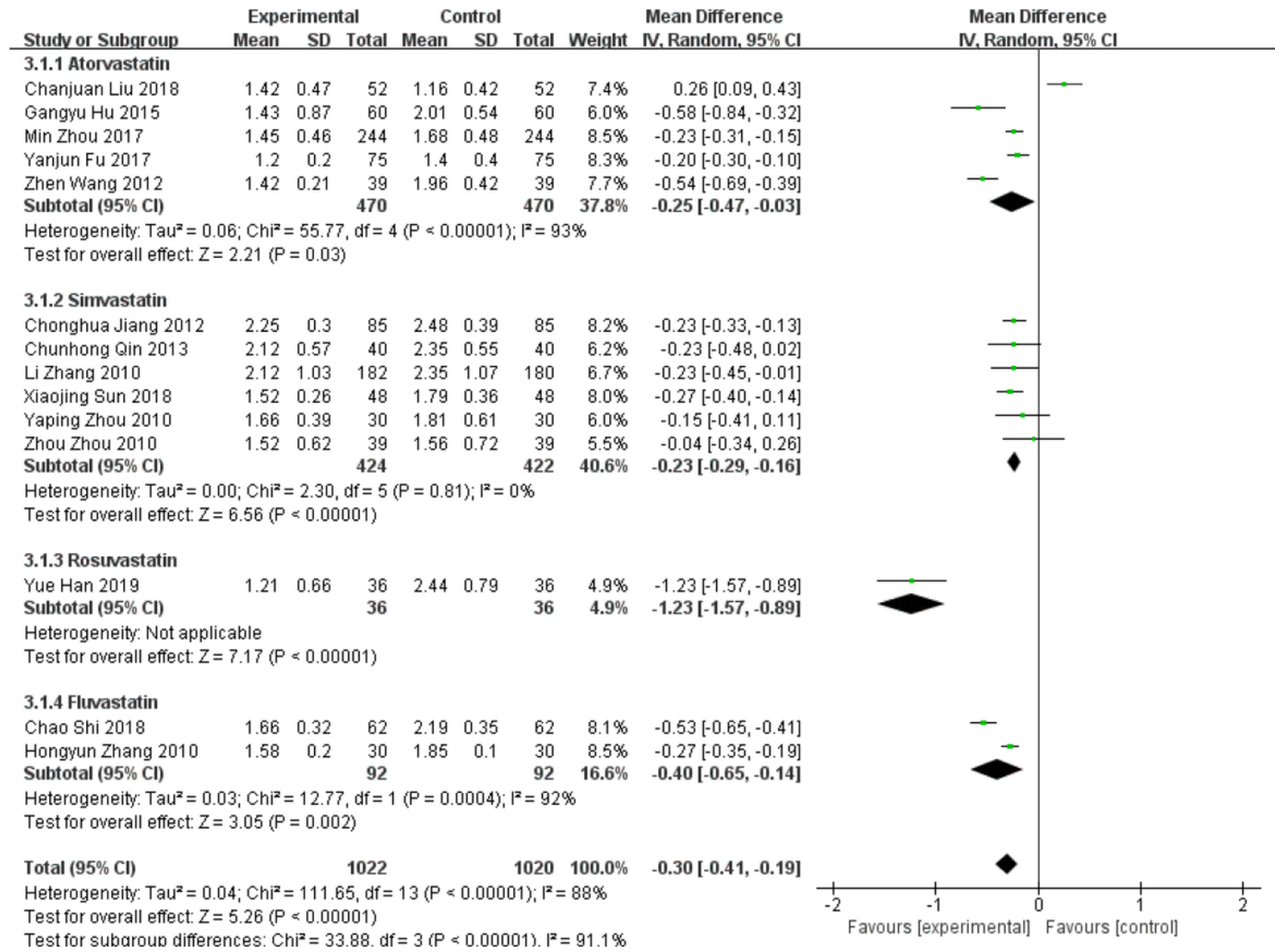

\section{Figure 6}

Comparison of TG between statin in combination with Xuezhikang and statin only in all 14 studies which were divided into 4 subgroup according to different statins. 


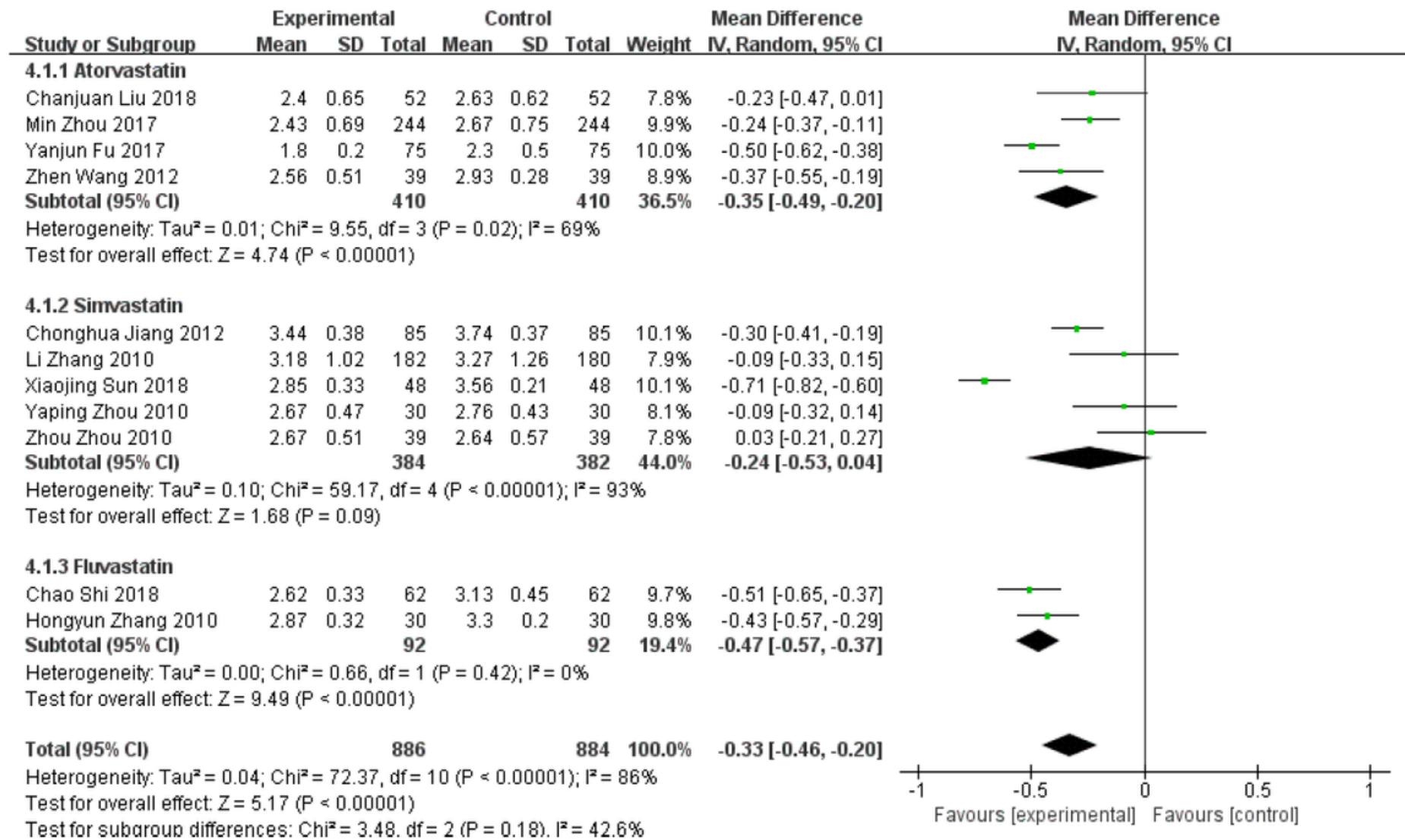

\section{Figure 7}

Comparison of LDLC between statin in combination with Xuezhikang and statin only in 11 studies which were divided into 3 subgroup according to different statins. 


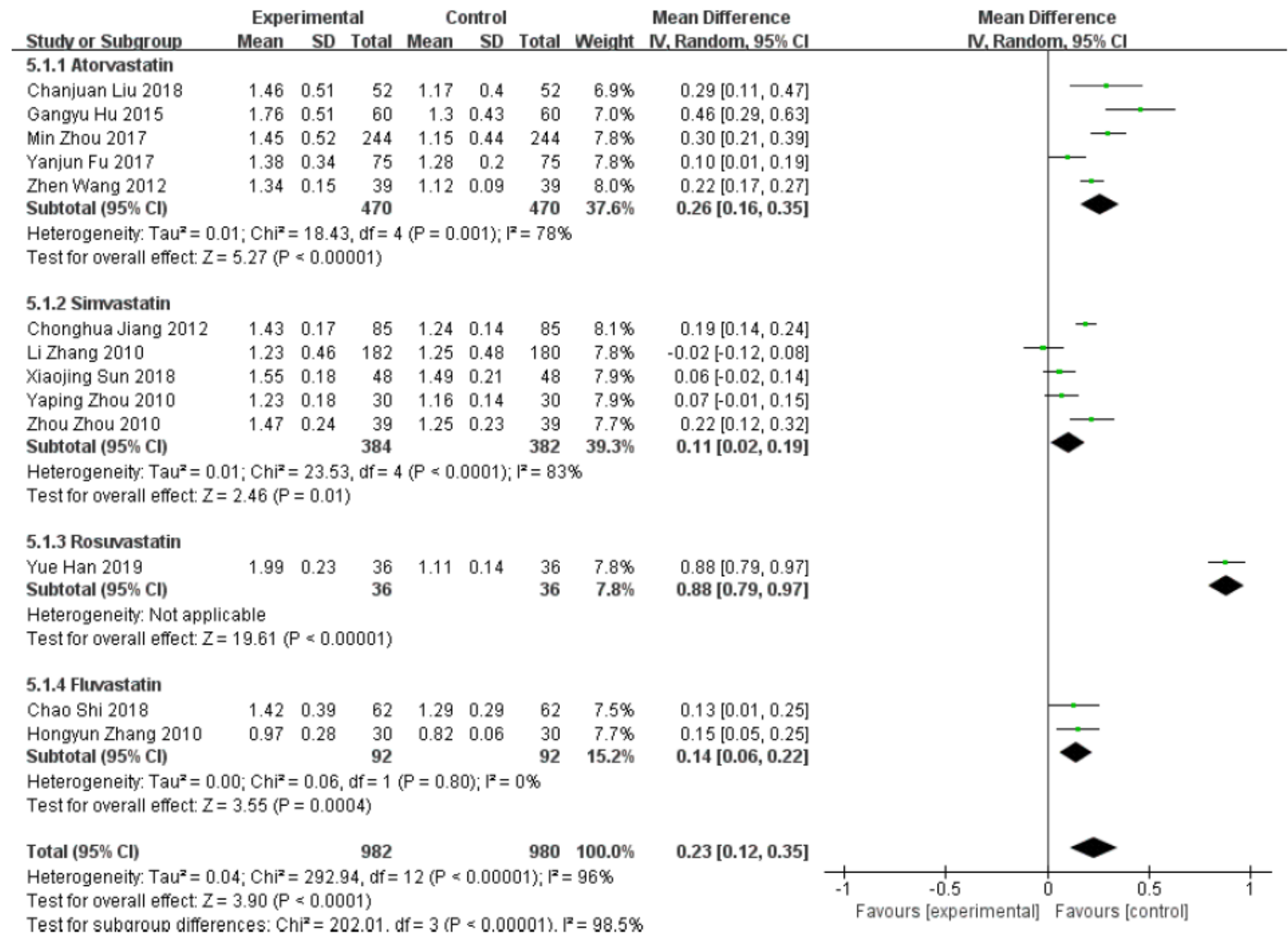

\section{Figure 8}

Comparison of HDLC between statin in combination with Xuezhikang and statin only in 13 studies which were divided into 4 subgroup according to different statins. 
Experimental Control Odds Ratio

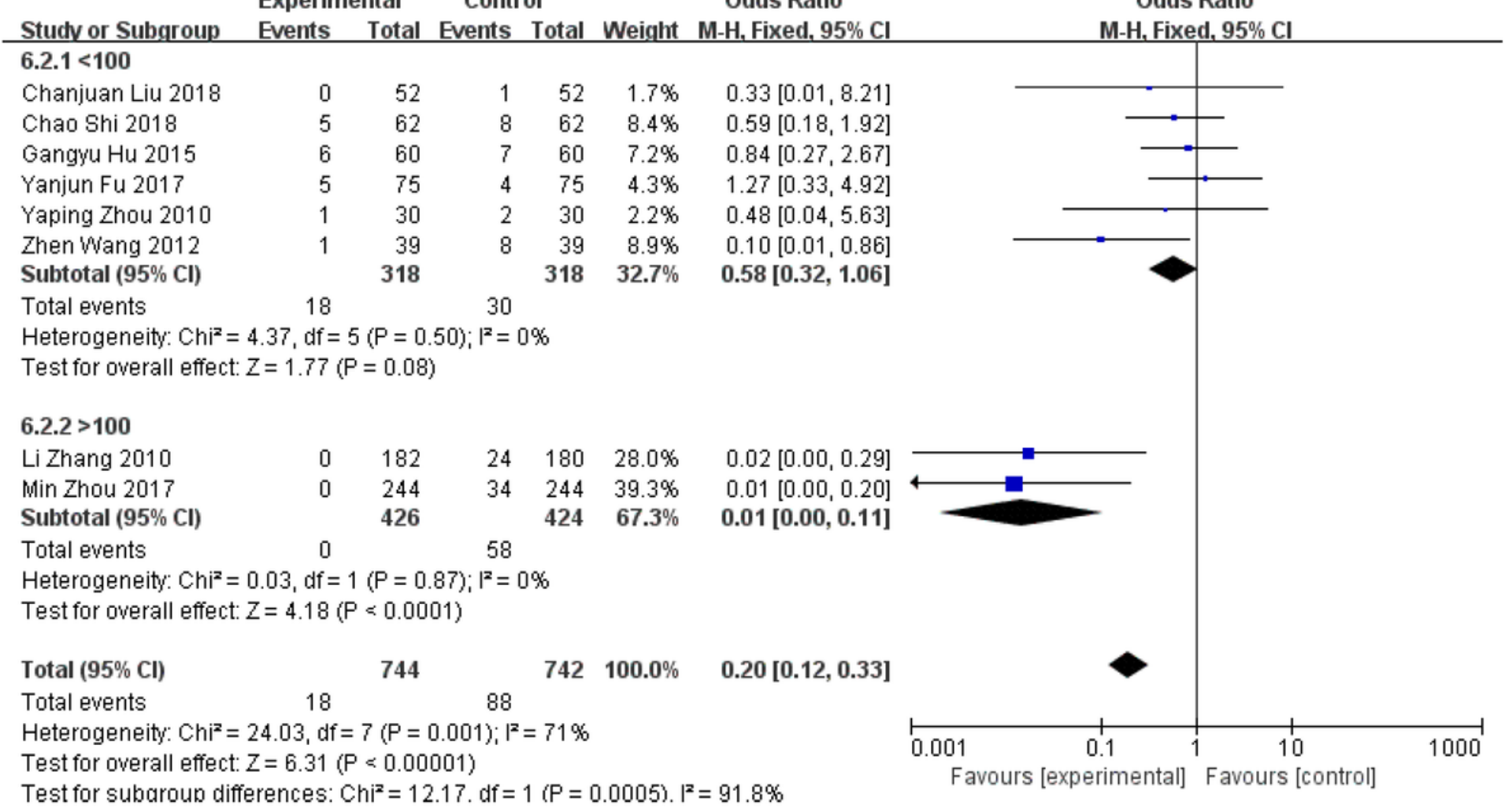

\section{Figure 9}

Adverse event of 8 studies in which statins combined with Xuezhikang were compared with statin alone were divided into 2 subgroups based on whether the patients included were more than 100 . 